\title{
Tool selection during foraging in two species of funnel ants
}

István Maák ${ }^{1}$, Gábor Lőrinczi ${ }^{1}$, Pauline Le Quinquis ${ }^{2}$, Gábor Módra ${ }^{1}$, Dalila Bovet ${ }^{3}$, Josep Call ${ }^{4}$, Patrizia d'Ettore ${ }^{2}$

${ }^{1}$ Department of Ecology, University of Szeged, Közép fasor 52, H-6726 Szeged, Hungary, bikmakk@gmail.com

${ }^{2}$ Laboratory of Experimental and Comparative Ethology, University Paris 13 Sorbonne Paris Cité, France

${ }^{3}$ Laboratoire Ethologie Cognition Développement, Université Paris Ouest Nanterre La Défense, France

${ }^{4}$ School of Psychology \& Neuroscience, University of St Andrews, UK

Corresponding authors:

István Maák - Department of Ecology, University of Szeged, Közép fasor 52, H-6726 Szeged, Hungary, e-mail: bikmakk@gmail.com, tel: +36-70-2793398

Patrizia d'Ettore - Laboratory of Experimental and Comparative Ethology, University Paris 13, Sorbonne Paris Cité, 99 Avenue J.-B. Clément, 93430 Villentaneuse, France e-mail: dettorre@leec.univ-paris13.fr, tel: +33-1-49403196 


\section{Tool selection during foraging in two species of funnel ants}

\section{Highlights}

- Some ant species use debris as tools to transport liquid food to the nest.

- When given the choice between different kinds of potential tools ants are selective.

- They show preference for materials with optimal handling and/or soaking properties.

- They can employ artificial materials novel to them, thus tool use is flexible in ants. 


\section{Tool selection during foraging in two species of funnel ants}

\section{ABSTRACT}

3 Tool use by non-human animals has received much research attention in the last couple of

4 decades. Nonetheless, research has focused mostly on vertebrates, particularly primates and

5 corvids, even though tool use has also been documented in insects. One of the best-

6 documented examples involves ants using debris (e.g., sand grains, mud, leaf fragments) to

7 collect and transport liquid food to their nest. However, little is known about the factors that

8 determine the selection of materials to be used as tool. We investigated tool selection in two

9 species of Aphaenogaster ants by giving them the choice between different kinds of potential

10 tools (natural and artificial objects). Ant workers showed a clear preference for certain

11 materials to be used as tool objects. Tool selection was also shaped by familiarity with the

12 material as ants developed a preference for artificial tools with a good soaking capacity that

13 cannot be found in their natural environment. Our results indicate that ants of this genus

14 evolved unique foraging strategies and show plasticity in their behaviour.

15 Keywords: ants, Aphaenogaster, foraging, food transport, tool use 
17 Once considered unique to humans, tool use is now known to be widespread in the animal 18 kingdom (Bentley-Condit \& Smith, 2010; Shumaker, Walkup, \& Beck, 2011). Moreover, in

19 the last two decades our general understanding of the mechanisms underlying flexible tool use

20 has significantly increased (Sanz, Call, \& Boesch, 2013). Some species can make tools to 21 meet specific task demands (e.g., Auersperg, Szabo, von Bayern, \& Kacelnik, 2012; Bird \& 22 Emery, 2009; Sanz, Call, \& Morgan, 2009), use multiple tools in succession to fulfil the subgoals required to complete a task (Martin-Ordas, Schumacher, \& Call, 2012; Mulcahy, Call, \& Dunbar, 2005; Wimpenny, Weir, Clayton, Rutz, \& Kacelnik, 2009) or select appropriate tools depending on their physical attributes or functional properties (Bird \& Emery, 2009; Chappell \& Kacelnik, 2002; Manrique, Gross, \& Call, 2010; Visalberghi et al., 2009).

Although these findings are concerned with vertebrates, mostly primates (chimpanzees, orangutans and capuchin monkeys) and passerine birds (New Caledonian crows, rooks, woodpecker finches) (Sanz et al., 2013), tool use also occurs in invertebrates.

30 For instance, a recently compiled catalogue reports about 50 cases of tool use in insects, involving 30 different genera (Bentley-Condit \& Smith, 2010). However, little is known about the occurrence of flexible tool use in invertebrates. For instance, weaver ants use the silk produced by their larvae in nest building but this is not considered "true" tool use because ants use an animate object (Pierce, 1986). Antlions and wormlions throwing out sand to make small prey fall inside their conical pits does qualifies as tool use. Although it is a fairly stereotyped behaviour, it is not completely fixed: antlions modify the characteristics of their trap according to hunger level, prey availability, predation threat and other environmental conditions such as light and temperature; however, the influence of experience upon this flexibility is unclear (Scharf, Lubin \& Ovadia, 2011). Antlions and wormlions also prefer specific substrates for pit building or ambushing prey (Devetak \& Arnett, 2015). The use of pebbles to close burrows containing eggs and prey in some apoid wasps (Ammophila, Sphex) is flexible because it requires the selection of suitable pebbles (Evans \& Eberhard, 1970). transport food by some species of ants including the harvester ant Pogonomyrmex badius (Morrill, 1972), Solenopsis invicta (Barber, Ellgaard, Thien, \& Stack, 1989), and several 
species of Aphaenogaster (Agbogba, 1985; Fellers \& Fellers, 1976; McDonald, 1984; Tanaka \& Ono, 1978), all belonging to the subfamily Myrmicinae. Many of the species from this subfamily are characterised by a very chitinous gaster (abdomen) and by the lack of a distensible crop, which prevents the transportation of large amounts of liquid food inside their bodies, a feature very common in other subfamilies, such as Formicinae or Dolichoderinae (Davidson, Cook, \& Snelling, 2004; Hölldobler \& Wilson, 1990). Furthermore, some myrmicine genera, namely Aphaenogaster, do not perform trophallaxis (Delage \& Jaisson, 1969) (i.e., mouth-to-mouth exchange of liquid food, also common in other subfamilies) and as a consequence the foragers of these species cannot exchange liquids stored in their crops with in-nest workers performing other tasks, such as feeding the larvae. The characteristic anatomy of the digestive tract in myrmicine ants, in particular the absence of an expandable crop, may have favoured the evolution of tool using behaviour, which allows for an efficient gathering, transport and sharing of liquid food (Fellers \& Fellers, 1976; Tanaka \& Ono, 1978).

When foragers of these myrmicine species encounter liquid food sources (e.g., fruit pulp, body fluids of dead arthropods) they drop debris of various kinds (e.g., sand grains, soil particles, leaf fragments) into the food source and then transport the food-soaked debris back into the nest. Furthermore, some evidence suggests that these ants do not drop debris into nonfood substances (Agbogba, 1985; Banschbach, Brunelle, Bartlett, Grivetti, \& Yeamans 2006). Tool-assisted food transportation has been observed in both field and laboratory experiments with artificial baits (Agbogba, 1985; Banschbach et al., 2006; Barber et al., 1989; Fellers \& Fellers, 1976; Fowler, 1982; Lőrinczi, 2014; McDonald, 1984; Morrill, 1972; Tanaka \& Ono,

68 1978). Ants use as tools different objects found near the food source including mud clods, leaf

69 fragments, pine needles, sand grains, or any particles of a suitable size (Banschbach et al.,

70 2006; Fellers \& Fellers, 1976; Lőrinczi, 2014; Morrill, 1972; Tanaka \& Ono, 1978). So far,

71 however, only one comprehensive study has been carried out on tool selectivity in these ants

72 (Tanaka and Ono, 1978). Other studies have reported limited observations that might indicate

73 selectivity in use of tools in Aphaenogaster species (e.g., Banschbach et al., 2006; Fellers \&

74 Fellers, 1976; Lőrinczi, 2014; Morrill, 1972). 
This putative material selectivity is important because it may indicate that ants choose materials flexibly, something that has been mainly documented in vertebrates. However, little is known about the factors that determine ants' preference for various materials as suitable tools for liquid transportation. The aim of this study was to comprehensively investigate material selectivity in liquid food transportation in two Aphaenogaster ant species in the

80 laboratory to assess their flexibility and establish a possible link with the literature on tool use in vertebrates. We adopted Bentley-Condit and Smith's (2010) definition of tool use, which in turn closely followed that of St Amant and Horton's (2008): “the exertion of control over a freely manipulable external object (the tool) with the goal of (1) altering the physical properties of another object, substance, surface or medium (the target, which may be the tool user or another organism) via a dynamic mechanical interaction, or (2) mediating the flow of information between the tool user and the environment or other organisms in the environment" p.1203. We chose this definition instead of Beck's (1980) or Pierce's (1986) because it provided a good balance between specificity and generality and crucially, it fully captured the behaviour that we investigated here.

We confronted ants with a liquid food source away from the nest and a set of natural or artificial (novel) objects with different weight/soaking properties. One might expect that tools with more efficient soaking properties would be preferred over alternative choices. Additionally, we expected that ants would preferentially drop debris in nutritious baits. The presentation of natural objects allowed us to link this study with previous ones while the inclusion of the artificial objects allowed us to explore the ants' flexibility in learning to use the most efficient novel materials.

\section{METHODS}

\section{Study species and housing}

99 We studied two monogynous Mediterranean ant species belonging to the subfamily 100 Myrmicinae, Aphaenogaster subterranea and Aphaenogaster senilis (Czechowski, 101 Radchenko, Czechowska, \& Vepsäläinen, 2012; Stukalyuk \& Radchenko, 2011). 102 A. subterranea (Latreille, 1798) is a highly thermophilous species distributed in southern and 103 central Europe (Czechowski et al., 2012; Seifert, 2007). It lives in moderately wet and warm 
deciduous and pine forests, and builds nests under stones, in the soil, litter or occasionally in fallen branches. Colony size can vary from several hundred up to 2000 workers (Czechowski et al., 2012; Seifert, 2007; Stukalyuk \& Radchenko, 2011). A. senilis (Mayr, 1853) inhabits open, sunny locations such as forest edges, lawns, fields and sand dunes. The nests are built into the soil, often sheltered by stones. Workers forage individually mostly at the ground level, but they can occur on shrubs and trees. Since these habitats have scarce food sources, workers can cover large areas with the help of their long legs. Colony size can vary between a few hundred to a few thousand workers (Boulay et al., 2007).

Eight medium sized colonies of A. subterranea (two queenright and 6 queenless, between 500-1500 workers) were collected in a black pine forest near the village of Litér (Hungary) and kept under standard conditions (temperature $24 \pm 4{ }^{\circ} \mathrm{C}$; relative humidity 42 43\%; 12 L: 12 D cycle) in the laboratory. Together with some material coming from the original habitat (soil, dried pine needles and leaf fragments), the colonies were kept in plastic boxes $(44 \mathrm{~cm} \times 31 \mathrm{~cm} \times 23 \mathrm{~cm})$ with their cover cut in a circular shape (diameter $15 \mathrm{~cm})$ and covered with a fine-wired metal mesh for ventilation and easy moistening of the nest. Every box containing a colony was connected with a $10 \mathrm{~cm}$ long plastic tube to an arena $(60 \mathrm{~cm} \times$ $30 \mathrm{~cm} \times 15 \mathrm{~cm}$ ). They were watered daily, and fed every second day with a commonly used artificial diet (Bhatkar \& Whitcomb, 1970) in a distant location of the foraging arena. During the experimental period the colonies were not fed, to increase motivation for food found on the baits. Water was always provided ad libitum.

Three queenright colonies of A. senilis (colony size 500-1500 workers) were collected at Banyuls-sur-Mer (France) in a sandy area and kept in the laboratory under standard conditions (temperature $24 \pm 4{ }^{\circ} \mathrm{C}$; relative humidity 50-60\%; $12 \mathrm{~L}: 12 \mathrm{D}$ cycle). They were housed in artificial nests, each consisting of a cylindrical plastic box (diameter $12.5 \mathrm{~cm}$ ) with regularly moistened plaster floor, and a hole giving access to the foraging area, which was represented by the space left in a larger plastic box $(18 \mathrm{~cm} \times 25.5 \mathrm{~cm} \times 7.7 \mathrm{~cm})$ containing the circular nest. The standard diet for each colony consisted of five dead crickets (Acheta domestica) and about $5 \mathrm{~g}$ of apple/honey mix two times per week. During the experimental period, to increase motivation for food, colonies were fed with only three crickets and $2 \mathrm{~g}$ of apple/honey mix (twice a week); water was always provided ad libitum. 
135 Ant colonies were presented with food baits and different types of potential tools in the 136 foraging arena (Fig. 1, 2). The methodology used in A. subterranea and A. senilis and 137 described below is slightly different because this study is the combined output of two initially

138 separate studies conducted independently in two different laboratories.

139 Aphaenogaster subterranea

140 The duration of the experiments was 3 hours, which was enough time to observe the transport 141 of tools into the nests. Each observation period lasted one minute, repeated every four minutes 142 until the end of the experiment. During this time we noted the number of tools transported to 143 the bait and from the bait into the nests. Tool preference was tested for tools found and used 144 in nature: small soil grains (diameter $1 \mathrm{~mm}$ ), large soil grains (diameter 2-3 mm), and 145 fragments of pine needles and leaves. Additionally, we also used a fifth tool type of 146 anthropogenic origin with good soaking/weight ratio: small pieces of sponges (diameter 5 $147 \mathrm{~mm}$ ) (Fig. 1 and Fig. A1, appendix). Tools were placed at a distance of $12 \mathrm{~cm}$ from the baits 148 in a random order. To estimate the soaking properties, the weight of 10 tools of each type was 149 measured with a precision analytical balance (10 $\mathrm{mg}$ accuracy) before and after soaking them 150 in the different types of baits (Table 1). The objects were placed on the surface of the baits 151 and left there for 10 minutes. Three different baits were tested: water, honey diluted in water 152 (1:3 ratio; further honey-water) and honey (condensed with sugar powder; further honey) 153 placed in plastic plates (diameter $4 \mathrm{~cm}$, Fig. 1 and A1). The baits were given to the colonies in 154 a random order.

\section{Aphaenogaster senilis}

157 The experiments lasted 3 hours, during which the activity of the colonies was videotaped. The 158 tapes were analysed as for A. subterranea. The experiments with the same setup were 159 repeated 10 times per each colony.

160 Tool use preference was tested for a total of 6 different, novel potential tools, such as pieces 161 of paper, sponges, artificial foam, twigs, string and parafilm (Fig. 2). Groups of 10 tools of 
each type (average weight for each tool: $2.5 \mathrm{mg}$ ) were placed $12 \mathrm{~cm}$ from the food source (diluted honey on a piece of aluminium foil). The soaking properties were estimates by measuring the weight of 10 tools of each type with a precision analytical balance $(10 \mathrm{mg}$ accuracy) before and after soaking them in diluted honey (Table 2).

\section{Ethical Note.}

Ant colonies were collected with care in the field and maintained in nearly natural conditions in the laboratory. Ants were provided with suitable nesting sites, food and water thus minimizing any adverse impart on their welfare. Our experimental designs include only beahvioural observations, no insect was harmed or stressed during the experimental procedure and all ant colonies were healthy at the end of the experiments.

\section{Statistical analysis}

In A. subterranea, we did not observe any transport of tools into the nests in the case of water baits; furthermore, the transport rate towards the water baits was much lower than towards the other baits, so we focused on the analysis of tool use in honey-water and honey baits. The effect of the bait type on the total number of tools dropped into the baits was analysed using a GLMM model (Poisson errors, maximum likelihood fit, log link). In the full model, bait type was included as a factor and colony ID as a random factor $(N=12)$ to account for within colony similarities. Differences in the number of tools dropped into baits by different colonies according to different tool types were analysed with GLMM models (Poisson errors, maximum likelihood fit, log link). In the full model, tool type was included as a fixed factor and colony ID as a random factor $\left(N_{A . s u}=30, N_{A . s e}=18\right)$.

3 The transport rate of tools towards the baits for the colonies of both species was analysed with the help of Log-rank test with Montecarlo (100.000) simulations $\left(N_{A . s u}=60\right.$ corpses, $N_{\text {A.se }}=$ 30). The removal rate was tested until at most the $10^{\text {th }}$ piece of tools was removed. The different tool types were included as dummy variables, while colony ID was included as a random factor. The transport rate of the different tools into the nests was analysed with the same model construction in both species. 
In A. subterranea, the transport of tools to the different baits was analysed in separate

190 models, and because 2 colonies did not transport anything to the baits, only 6 colonies were

191 used for the analysis. In A. senilis, the same model constructions were used for the analysis of

192 the $1^{\text {st }}$, the 5 th and $10^{\text {th }}$ experiment. The three-hour experimental period was enough in the

193 case of both species to observe the transport of tools into the nests. In A. subterranea, 3

194 colonies in the case of honey-water, and 6 colonies in the case of honey baits were actively

195 transporting tools into their nests, so only these colonies were used in the analysis with the

196 same model constructions as described before $\left(N_{\text {honey-water }}=15, N_{\text {honey }}=30\right)$. All statistical

197 analyses were carried out in R (version 3.0.2, The R Foundation for Statistical Computing,

198 Vienna, Austria, http://www. r-project.org). GLMMs were performed using glmer function in

199 Ime4 package (Bates, Maechler, Bolker, \& Walker, 2013). In the analyses, all tools used were

200 included. Log Rank Test was carried out with the surv_test function in coin package

201 (Hothorn, Hornik, van de Wiel, \& Zeileis, 2008). Pairwise comparisons were performed with

202 separate Log Rank Tests and the Relevel function was used to carry out post-hoc sequential

203 comparisons among factor levels when performing GLMM analyses. We applied table-wide

204 sequential Bonferroni-Holm correction to reveal the exact significance levels in these cases.

205 RESULTS

206 Aphaenogaster subterranea: transport to the baits

207 Workers of A. subterranea dropped significantly more tools into honey-water (GLMM: $z=$ $20812.5, N=24, P<0.001)$ and honey $(z=11.97, P<0.001)$ than into water, but no difference 209 was observed between the honey-water and honey $(z=-0.96$, NS). We therefore concentrate 210 on honey-water and honey baits in the following analyses.

211 Overall, small soil grains were the most frequently transported tool to the honey-water, 212 and their number was significantly different from the number of sponges $(z=-3.33, P<$ 
213 0.001) and leaf fragments (Fig. 3), with the latter being the least frequently dropped tools 214 compared to every other tool type $(z<-3.22, P<0.01)$. Furthermore, leaf fragments were 215 transported at the lowest rate (Log Rank Test: $\left.13<\chi^{2}<29.76, P<0.001\right)$ while sponges were 216 transported at a slower rate than small soil grains $\left(\chi^{2}=29.76, P<0.01\right)$ (Fig A2).

217 In the case of honey baits, the preferred tools were the small soil grains and pine 218 needles, which were transported in significantly higher numbers than leaf fragments $(z<-$ $2193.07, P<0.001)$ and large soil grains $(z<-2.65, P<0.05)$; sponges were also used more 220 frequently than leaf fragments $(z=-2.83, P=0.03)$ (Fig. 3). Every tool type was transported 221 at a faster rate than leaf fragments $\left(11.5<\chi^{2}<40.29, P<0.003\right)$ (Fig. A2).

Aphaenogaster subterranea: transport into the nests

In the case of honey-water baits, small soil grains were transported into the nest in 224 higher numbers than pine needles $(z=3.43, N=24, P<0.001)$, leaf fragments $(z=3.56, P<$ $2250.001)$ and sponges $(z=2.91, P<0.001)$ (Fig 4). Small soil grains were transported also at a 226 faster rate than every other tool type $\left(11.43<\chi^{2}<29.26, P<0.003\right)$ (Fig. A3).

In the case of honey baits, sponges were transported into the nest in highest numbers, 228 which differed significantly from every other tool type $(z<-4.02, P<0.001)$. The second 229 most preferred tools were small soil grains, which were transported significantly more often 230 than leaf fragments $(z=-2.79, P=0.03)$ (Fig 4). Sponges were transported at a faster rate than 231 every other tool type $\left(8.56<\chi^{2}<37.39, P<0.01\right)$. Leaf fragments were transported at the 232 slowest rate, which significantly differed from the small $\left(\chi^{2}=22.31, P<0.001\right)$ and large soil 233 grains $\left(\chi^{2}=7.07, P<0.05\right)($ Fig A3).

Aphaenogaster senilis: transport to the baits

Overall, the number of tools used by A. senilis workers significantly changed across 236 trials (from the $1^{\text {st }}$, to the $5^{\text {th }}$ and the $10^{\text {th }}$ trials: GLMM: $z=3.09, N=36, P<0.01$ ), and there 237 was no significant difference between the $5^{\text {th }}$ and the $10^{\text {th }}$ trial $(z=0.95$, NS), therefore the use 238 of potential tools was analysed separately for each trail (Fig. A4). 
In the $1^{\text {st }}$ and $5^{\text {th }}$ trials, there was no significant difference in the number of different 240 tools transported to the bait (between every tool type $1^{\text {st }} z>0.2, N=18, \mathrm{NS} ; 5^{\text {th }} z>-2.2, N=$ 241 18, NS) (Fig. 5), although in the $1^{\text {st }}$ trial paper was transported at a significantly faster rate 242 than the artificial foam (Log Rank Test: $\chi^{2}=12.72, P<0.01$; Fig. A5). In the $5^{\text {th }}$ trial, the 243 sponges (Log Rank Test: $\chi^{2}=-4.33, P<0.05$; Fig. A5) and the pieces of paper (Log Rank 244 Test: $\left.\chi^{2}=-3.82, P<0.05\right)$ were transported significantly faster than every other tool types, but 245 there was no significant difference between these two tool types (Log Rank Test: $\chi^{2}=-0.28$, 246 NS), and paper did not differ significantly from string (Log Rank Test: $\chi^{2}=-2.33$, NS; Fig. 247 S5).

In the 10th trial, the preferred tools were paper and sponges $\left(\chi^{2}=0.89, \mathrm{NS}\right)$, which were used more frequently than artificial foam $(z>3.24, N=18, P<0.01$, Fig. 5) and transported at a significantly faster rate than parafilm and twigs (respectively: $\chi^{2}>8.66, P<$ 0.05 and $\chi^{2}>8.22, P<0.05$, Fig. A5). Artificial foam was transported at a significantly slower rate than every other tool type $\left(\chi^{2}=9.3, P<0.05\right.$, Fig. A5).

\section{Aphaenogaster senilis: transport into the nest}

Overall, the number of tools transported into the nest by A. senilis workers significantly changed across trials (GLMM: $z=2.79, N=36, P<0.01$ ), and there was no significant difference between trial $5^{\text {th }}$ and $10^{\text {th }}(z=1.01$, NS), therefore the use of artificial tools was analysed separately for the $1^{\text {st }}, 5^{\text {th }}$ and $10^{\text {th }}$ trials (Fig. A4).

In the first trial, there was no significant difference in the number (GLMM: $1.82>z$ $259>0.001, N S)$ and transport speed (Log Rank Test: $0>\chi^{2}>1$, NS) of different tools brought 260 into the nest (Fig. 6 and Fig. A5). In contrast, in the $5^{\text {th }}$ trial the pieces of papers and sponges 261 were transported in a significantly higher number than the foam $(z>-3.16, P<0.05)$ and 262 parafilm tools $\left(z>-3.38, P<0.01\right.$; Fig. 6). Moreover, paper and sponge (Log Rank Test: $\chi^{2}=$ 2630.29 , NS) were transported at a higher rate than every other tool type $\left(\chi^{2}>2.85, P<0.05\right.$; 264 Fig. S5). Strings and twigs $\left(\chi^{2}=-0.91\right.$, NS) were transported at a higher rate than foam $\left(\chi^{2}>\right.$ 265 6.24, $P<0.01)$ and parafilm $\left(\chi^{2}>2.48, P<0.05\right.$; Fig. A5). 
In the $10^{\text {th }}$ trial, paper was the most frequently transported tool to the nest, differing significantly from the number of artificial foam $(z=2.73, P<0.05)$ and parafilm tools $(z=$ 2.73, $P<0.05$ ) (Fig. 6). The fastest transport rate was observed for paper tools, which differed significantly from every other tool type $\left(\chi^{2}>8.2, P<0.05\right.$, Fig. A5) except for sponges and strings $\left(\chi^{2}>6.78\right.$, NS, Fig. A5). Parafilm and artificial foam $\left(\chi^{2}=3.35\right.$, NS $)$ were transported at a significantly slower rate than every other tool type $\left(\chi^{2}>8.66, P<0.05\right)$.

\section{DISCUSSION}

273 We observed the occurrence of tool use to transport liquid food in two ant species of the 274 genus Aphaenogaster thus confirming previous observations (Agbogba, 1985). More 275 importantly, ant workers were selective in both the materials they chose and the baits that they exploited. A. subterranea was mainly tested with natural materials. Small soil grains were the most preferred item and leaf fragments, despite having a superior soaking power than soil grains, the least preferred item. Ants showed a remarkable preference for sponges despite being novel (they were the only artificial material tested in this species). Interestingly, ant workers in more than $80 \%$ of the trials broke the sponges into smaller fragments, presumably to facilitate handling. Once tools were dropped into the baits, ants behaved differently depending on the bait's viscosity (honey-water or pure honey). Imbibed small soil grains were transported to the nest in the highest numbers and faster than other tool types from honeywater baits, while sponges were the preferred transported tools from the honey baits (small soil grains were the second preferred tool to be brought to the nest). Additionally, ants threw much fewer items into water baits compared to those baits that contained honey.

A. senilis could choose among six materials that differed in terms of soaking power (paper, sponges, artificial foam, twigs, sting and parafilm). It is likely that ants of this species, which live in sandy areas, were unfamiliar with most of these materials. Initially, A. senilis showed no preference for any of the tools for dropping them into the baits, although paper was transported faster to the bait compared to the artificial foam. However, along trials, ants significantly preferred dropping paper and sponges into the baits, thus choosing in accordance

293 with the tools' soaking properties. A similar pattern was observed for tool transportation to 
294 the nest: ants developed a preference for paper, followed by sponges, thus optimizing their 295 foraging effort by using the tools with the best soaking properties and ease of grasping 296 compared to other tool types.

297 Our results suggest that tool use to transport liquid to the nest in the two studied ant 298 species is not behaviourally fixed. Ants incorporated novel tools, many of them made of 299 artificial materials, into their foraging activities. Moreover, A. senilis learned within 10 trials 300 to select the best tool options available based on their soaking properties and A. subterranea 301 chose tools in relation to the characteristic of the food itself, e.g., food viscosity. This means 302 that ants can select tools according to both food and tool properties. Nevertheless, other 303 factors (besides a tool's soaking properties) may have played a role in determining ants' 304 preferences. One possibility is that the low density of some materials in the natural habitat 305 (e.g., leaf fragments are not abundant in the pine forest inhabited by these A. subterranea 306 colonies) may have been the reason for largely ignoring this item. However, a lack of 307 familiarity with potential tools cannot explain why A. subterranea used sponge pieces, which 308 were totally novel objects. Even more compelling are the data on A. senilis, which developed 309 a preference for unfamiliar materials during testing.

Handling effort is another factor that could have played an important role in tool 312 selection, perhaps in combination with the tool's soaking properties. During our observations 313 we noticed that $A$. subterranea workers had problems with grasping, handling and orienting 314 the leaf fragments, while the pieces of sponges could be grasped more easily. In fact, ants may 315 have torn apart sponges to reduce their size and facilitate handling. Although the soaking 316 power of sponges was lower when dropped into honey than into honey-water, their relatively 317 low weight made them more buoyant than other tool types and their irregular texture 318 increased their potential for being grasped. We found that the preference for particular items 319 often depended on the type of task that ants carried out. In particular, sponges may have been 320 preferentially transported to the nest, but small soil grains were the most dropped tools into 321 the baits. This suggests that selection among different tool types occurred both when first 322 encountered and also at the food source after the tools had been dropped into the baits. This 323 two-stage selection process might be especially important in the case of novel tools whose 324 properties are still unknown. Indeed, A. senilis ants transported very few foam fragments to 
325 the bait in the first trial but subsequently increased their transportation during the $5^{\text {th }}$ trial. 326 Nevertheless, foam fragments were rarely transported from the bait to the nest and by the $10^{\text {th }}$ 327 trial ant workers even reduced their transportation to the baits. This suggests that tool 328 selection, after familiarization with novel material, may have also occurred at the baits. Other 329 authors observed that not all the tools dropped into the baits were transported into the nest 330 (Fowler, 1982; McDonald, 1984), corroborating our interpretation that further tool selection can occur once the tools have been dropped into the liquid food source.

333 the material to a desired form are therefore important factors in tool selection. The assessment 334 of these characteristics appears to be the result of a familiarization and learning process, at 335 least for the novel objects offered to the ants in our experiments. As the natural availability of 336 certain kinds of tools varies both spatially and seasonally, plasticity in tool selection is likely 337 to be adaptive. Tool use behaviour in ants may have evolved from the tendency shown by 338 many species to cover with debris liquid or viscous substances, which may otherwise cause 339 drowning or entanglement of workers near their nest (Fellers \& Fellers, 1976; McDonald, 340 1984). Note, however, that it has been experimentally shown that Aphaenogaster ants 341 typically drop debris in food substances (Agbogba 1985; Banschbach et al., 2006) and our 342 experiments confirm this. The adaptive advantage of tool use in Aphaenogaster ants is that, 343 by using tools, foragers are capable of efficiently exploiting ephemeral food sources by 344 transporting much larger quantities of liquid nutrients than they could do by internal transport 345 (Fellers \& Fellers, 1976; Tanaka \& Ono, 1978), given the non-expandable crop characteristic 346 of myrmicine ants. Tool use might help these ants to compete with more dominant ant species 347 which are able to monopolize food sources by numbers: if the food is quickly covered by 348 debris, other ant species cannot exploit it and tool users can take the necessary time to bring 349 the soaked debris back to their nest (Banschbach et al., 2006; Fellers \& Fellers, 1976). We began our paper by referring to the research on flexible tool use in vertebrates 351 hoping to establish a link with the existing observations on invertebrate tool use. Our 352 experiments showed some indication that ants preferred materials with good soaking power 353 although other aspects such as ease of grasp may have also contributed to their choices. 354 Chimpanzees create a vegetable mass with good absorbent properties by chewing leaves that 
they use to extract liquid from crevices (Goodall, 1986). It is unknown, however, whether chimpanzees select certain plant species for their high soaking power. In a liquid extraction task in the laboratory, Lehner, Burkart and van Schaik (2011) reported that captive orangutans developed liquid extraction techniques based on materials with high soaking power (e.g., wood wool, paper) over those with low soaking power (e.g., leafless branch). Although this may indicate that orangutans, like ants, were sensitive to the properties of such materials, the lack of a direct and systematic comparison between different kinds of materials considerably reduces the conclusions that one may be able to draw from that study. Nevertheless, other studies with vertebrates in non-liquid extractive foraging tasks have systematically varied the materials presented and have found evidence of selectivity in terms of hardness and weight (Visalberghi et al., 2009), weight (Bird \& Emery, 2009) or rigidity (Manrique et al., 2010). Our findings with ants are in some ways comparable to those studies although admittedly, our results are less clear than those reported in vertebrates. This is partly understandable because our study is only the second systematic study on material selectivity in ants (besides Tanaka and Ono, 1978) and we may have not fully considered a number of factors. For instance, dropping a substantial number of tools (e.g., pine needles) inside the liquid and abandoning them there may seem puzzling from the point of view of efficiency. Note, however, that dropping those materials on the liquid may have accomplished another function (e.g., preserving the liquid food against exploitation from other species). Also, the absorbed liquid may have altered the potential for grasping the potential tool object or increased its weight in excess.Another possibility is that ants can only identify suitable materials after observing its effect on the substance to be collected instead of selecting them prior to their use (e.g., artificial foam). Although selecting materials to collect liquid has not been described in corvids or primates, selecting and manufacturing tools prior to their use is well-documented in those taxa (e.g., Manrique et al., 2010; Sanz , Call \& Morgan, 2009; Visalberghi et al., 2009; Wimpeny et al., 2009). Whether ants (or any other species) can also select new materials prior to experiencing its absorbent properties is an open question that future studies should address.

Some authors may question our use of the term tool use to describe the behaviour of the ants. Tool use is after all a contentious term in the literature typically characterized by rather long definitions, a number of clear examples, and some areas of substantial 
disagreement (see Bentley-Condit \& Smith, 2010; Shumaker et al., 2011). Although we would be ready to accept a less contentious terminology such as 'material use', it is difficult to do so when chimpanzees using leaves to extract liquid from crevices is considered a classical example of tool use (Goodall, 1986). More importantly, we think that the behaviour of the ants meets one of the most important criteria that define tool use in foraging contexts (Beck, 1980; Bentley-Condit \& Smith, 2010; St Amant \& Horton, 2008), i.e., the use of an external object to affect the position or location of another object or substance. Obviously one could argue that nest building materials affect the position of other nesting materials, which is why some authors object to the idea of tool use and would perhaps like to see either a more restricted use of the term, or its complete abandonment for a wider term such as construction behaviour (Hansell \& Ruxton, 2008). Although we understand this position and the reasons for it, given the above considerations, we still prefer to refer to the behaviour of the ants as tool use, or the similar denomination of object use.

In conclusion, we observed A. senilis and A. subterranea using natural and artificial debris to collect and transport liquid food to their nests. We also documented the development of a preference for materials with optimal soaking properties in A. senilis although other factors such as familiarity and ease of grasping may have played a role in determining ants' choices. Additional studies are needed to better characterize the extent and limits of this form of flexible tool use particularly in relation to the existing forms of flexible tool use displayed by vertebrates.

\section{REFERENCES}

Agbogba, C. (1985). Observations sur la récolte de substances liquids et de sucs animaux chez deux espèces d'Aphaenogaster: A. senilis et A. subterranea (Hym. Formicidae). Insectes Sociaux, 32, 427-434.

Auersperg, A. M. I., Szabo, B., von Bayern, A. M. P., \& Kacelnik, A. (2012). Spontaneous innovation in tool manufacture and use in a Goffin's cockatoo. Current Biology, 22, 903-904. 
414 Banschbach, V. S., Brunelle, A., Bartlett, K. M., Grivetti, J. Y., \& Yeamans, R. L. (2006). Tool use by the forest ant Aphaenogaster rudis: ecology and task allocation. Insectes Sociaux, 53, 463-471.

417 Barber, J. T., Ellgaard, E. G., Thien, L. B., \& Stack, A. E. (1989). The use of tools for food transportation by the imported fire ant, Solenopsis invicta. Animal Behaviour, 38, 550552.

Bates, D., Maechler, M., Bolker, B., \& Walker, S. (2013). lme4: Linear mixed-effects models using Eigen and S4. $\mathrm{R}$ package version 1.0-5 http://CRAN.Rproject.org/package=lme4, published online 25 October 2013.

Beck, B.B. (1980). Animal tool behavior: the use and manufacture of tools by animals. New York, Garland Publishing STPM Press.

Bentley-Condit, V. K., \& Smith, E. O. (2010). Animal tool-use: current definitions and an updated comprehensive catalog. Behaviour, 147, 185-221.

Bird, C. \& Emery, N., J. (2009). Insightful problem solving and creative tool modification by captive nontool-using rooks. Proceedings of the National Academy of Sciences USA, 106, 10370-10375.

Bhatkar, A. \& Whitcomb, W. H. (1979). Artificial diet for rearing various species of ants. Florida Entomologist, 53, 229-232.

Chappell, J. \& Kacelnik, A. (2002). Tool selectivity in a non-mammal, the New Caledonian crow (Corvus moneduloides). Animal Cognition, 5, 71-78.

437 Czechowski, W., Radchenko, A., Czechowska, W., \& Vepsäläinen, K. (2012). The ants (Hymenoptera, Formicidae) of Poland with reference to the myrmecofauna of Europe. Warszawa, Poland: MIZ PAS.

Davidson, D. W., Cook, S. C., \& Snelling, R. (2004). Liquid feeding performances of ants (Formicidae): ecological and evolutionary implications. Oecologia, 139, 255-266. 
Delage, B. \& Jaisson, P. (1969). Etude des relations sociales chez des Fourrnis du genre Aphaenogaster. Comptes Rendus de l'Académie des Sciences Paris, 268, 701-703.

Devetak, D \& Arnett, A. (2015). Preference of antlion and wormlion larvae (Neuroptera: Myrmeleontidae; Diptera: Vermileonidae) for substrates according to substrate particle sizes. European Journal of Entomology, 112, 500-509.

Evans, H. E. \& Eberhard, M. J. W. (1970). The wasps. Ann Arbor, USA: The University of Michigan Press.

Fellers, J. H. \& Fellers, G. M. (1976). Tool use in a social insect and its implications for competitive interactions. Science, 192, 70-72.

Fowler, H. G. (1982). Tool use by Aphaenogaster ants: a reconsideration of its role in competitive interactions. The Bulletin of New Jersey Academy of Science, 27, 81-82.

Goodall, J. (1986). The chimpanzees of Gombe. Patterns of behavior. Cambridge, MA: The Belknap Press of Harvard University Press

Hansell, M. \& Ruxton, G. D. (2008). Setting tool use within the context of animal construction behaviour. Trends in Ecology \& Evolution, 23, 73-78.

Hothorn, T., Hornik, K., van de Wiel, M. A., \& Zeileis, A. (2008). Implementing a class of permutation tests: the coin package. Journal of Statistical Software, 28, 1-23, http://www. jstatsoft.org/v28/i08/.

Hölldobler, B. \& Wilson, E. O. (1990). The ants. Cambridge, USA: Belknap Press of Harvard University.

Hunt, G. R. \& Gray, R. D. (2002). Species-wide manufacture of stick-type tools by New Caledonian crows. Emu, 102, 349-353.

Lehner, S.R., Burkart, J.M., \& van Schaik, C.P. (2011). Can captive orangutans (Pongo pygmaeus abelii) be coaxed into cumulative build-up of techniques? Journal of Comparative Psychology, 125, 446-455.

Lörinczi, G. (2014). Some notes on the tool-using behaviour of the ant, Aphaenogaster subterranea (Hymenoptera: Formicidae). Tiscia, 40, 17-24. 
Manrique, H. M., Gross, A. N., \& Call, J. (2010). Great apes select tools based on their rigidity. Journal of Experimental Psychology: Animal Behavior Processes, 36, 409422.

Martin-Ordas, G., Schumacher, L., \& Call, J. (2012). Sequential tool use in great apes. PLoS One, 7, e52074.

McDonald, P. (1984). Tool use by the ant, Novomessor albisetosus (Mayr). Journal of New York Entomological Society, 92, 156-161.

Morrill, W. L. (1972). Tool using behaviour of Pogonomyrmex badius (Hymenoptera: Formicidae). Florida Entomologist, 55, 59-60.

Mulcahy, N. J., Call, J., \& Dunbar, R. I. M. (2005). Gorillas and orangutans encode relevant problem features in a tool-using task. Journal of Comparative Psychology, 119, 2332.

Pierce, J. D. (1986). A review of tool use in insects. Florida Entomologist, 69, 95-104.

Sanz, C., Call, J., Boesch, C. (2013). Tool Use in Animals: Cognition and Ecology. New York, USA: Cambridge University Press.

Sanz, C., Call, J., \& Morgan, D. (2009). Design complexity in the tool use of chimpanzees (Pan troglodytes) in the Congo basin. Biology Letters, 5, 293-296.

Scharf, I., Lubin, Y. \& Ovadia, O. (2011). Foraging decisions and behavioural flexibility in trap-building predators: a review. Biological Reviews, 86, 626-639.

Seifert, B. (2007). Die Ameisen Mittel- und Nordeuropas. Görlitz, Germany: Lutra Verlags und Vertriebsgesellschaft.

Shumaker, R. W., Walkup, K. R., \& Beck, B. B. (2011). Animal tool behavior: The use and manufacture of tool by animals. Baltimore, USA: The Johns Hopkins University Press.

St. Amant, R. \& Horton, T. (2008). Revisiting the definition of animal tool use. Animal Behaviour, 75, 1199-1208. 
494 Stukalyuk, S. V. \& Radchenko, V. G. (2011). Structure of multispecies ant assemblages 36.

497

Tanaka, T. \& Ono, Y. (1978). The tool use by foragers of Aphaenogaster famelica. Japanese Journal of Ecology, 28, 49-58.

499 Visalberghi, E., Addessi, E., Spagnoletti, N., Truppa, V., Ottoni, E., Izar, P., \& Fragaszy, D. 500 (2009). Selection of effective stone tools by wild capuchin monkeys. Current Biology, $19,213-217$.

502 Wimpenny J. H., Weir A. A. S., Clayton L., Rutz C., \& Kacelnik, A. (2009). Cognitive 503 Processes Associated with Sequential Tool Use in New Caledonian Crows. PLoS One, 504 4, e6471. 
506 Table 1. Soaking properties of the different tools used by Aphaenogaster subterranea.

Imbibed /Initial weight (weight ratio)

$\begin{array}{ccc}\text { Tool type } & \text { Honey-water } & \text { Honey } \\ \text { Sponges } & 7.45 & 1.29 \\ \text { Leaf fragments } & 1.94 & 11.9 \\ \text { Pine needles } & 1.33 & 1.85 \\ \text { Small soil grains } & 1.1 & 1.48 \\ \text { Large soil grains } & 0.7 & 0.64\end{array}$

507 Table 2. Soaking properties of the different tools used by Aphaenogaster senilis.

$\begin{array}{cc} & \text { Imbibed /Initial weight (weight ratio) } \\ \text { Tool type } & \text { Honey-water } \\ \text { Paper } & 28.37 \\ \text { Sponges } & 23.31 \\ \text { Artificial foam } & 6.37 \\ \text { Twigs } & 3.06 \\ \text { String } & 2.00 \\ \text { Parafilm } & 1.47\end{array}$

508 
510 Figure 1. Experimental setup and tool types offered to Aphaenogaster subterranea.

511 Figure 2. Experimental setup and tool types offered to Aphaenogaster senilis.

512 Figure 3. Number of different tools transported to honey-water (a) and honey (b) baits by 513 Aphaenogaster subterranea workers. Box plots show the median (internal line), quartiles and 514 range (whiskers). Different letters above boxes represent groups that differ significantly from 515 each other.

516 Fig. 4. Number of different tools transported into the nest from the honey-water (a) and honey 517 (b) baits by Aphaenogaster subterranea workers. Box plots show the median (internal line), 518 quartiles and range (whiskers). Different letter s above boxes represent groups that differ 519 significantly from each other.

520 Figure 5. Number of different tools transported to the baits in the $1^{\text {st }}, 5^{\text {th }}$ and $10^{\text {th }}$ trials by 521 Aphaenogaster senilis workers. Box plots show the median (internal line), quartiles and range 522 (whiskers).

523 Figure 6. Number of different tools transported into the nest in the $1^{\text {st }}, 5^{\text {th }}$ and $10^{\text {th }}$ experiment 524 by Aphaenogaster senilis workers. Box plots show the median (internal line), quartiles and 525 range (whiskers).

526 Appendix - Figure legends

527 Figure A1. Different tool types used for experiments with Aphaenogaster subterranea (a) 528 from left to right: small soil grains, sponges, pine needles, large soil grains, leaf fragments; (b) 529 the dynamics of bait covering with tools.

530 Figure A2. Estimated functions of tool transport time to honey-water (a) and honey (b) by 531 workers of Aphaenogaster subterranea (Log-rank test). Different tool types are depicted by 532 different colours. 
533 Figure A3. Estimated functions of tool transport time into the nest from the honey-water (a) 534 and honey (b) baits by Aphaenogaster subterranea workers (Log-rank test). Different tool 535 types are depicted by different colours.

536 Figure A4. Summed number of tools transported on the baits and into the nest during the 537 three trials (box plots show: median, quartiles and range). Different letters above boxes 538 represent groups that differ significantly from each other.

539 Figure A5. Estimated functions of tools transport time on the baits (a; c; e) and into the nests $540(\mathrm{~b}, \mathrm{~d}, \mathrm{f})$ in the $1^{\text {st }}(\mathrm{a}, \mathrm{b}), 5^{\text {th }}(\mathrm{c}, \mathrm{d})$ and $10^{\text {th }}(\mathrm{e}, \mathrm{f})$ experiment by Aphaenogaster senilis workers 541 (Log-rank test). Different tool types are depicted by different colours. 


\section{ACKNOWLEDGEMENTS}

Supported by European Commission (FP7-MC-ERG-2009-256524 to PdE). We thank Paul Devienne for technical advice and support and Christophe Féron for statistical advice. We are grateful to anonymous reviewers for their comments and suggestions. 


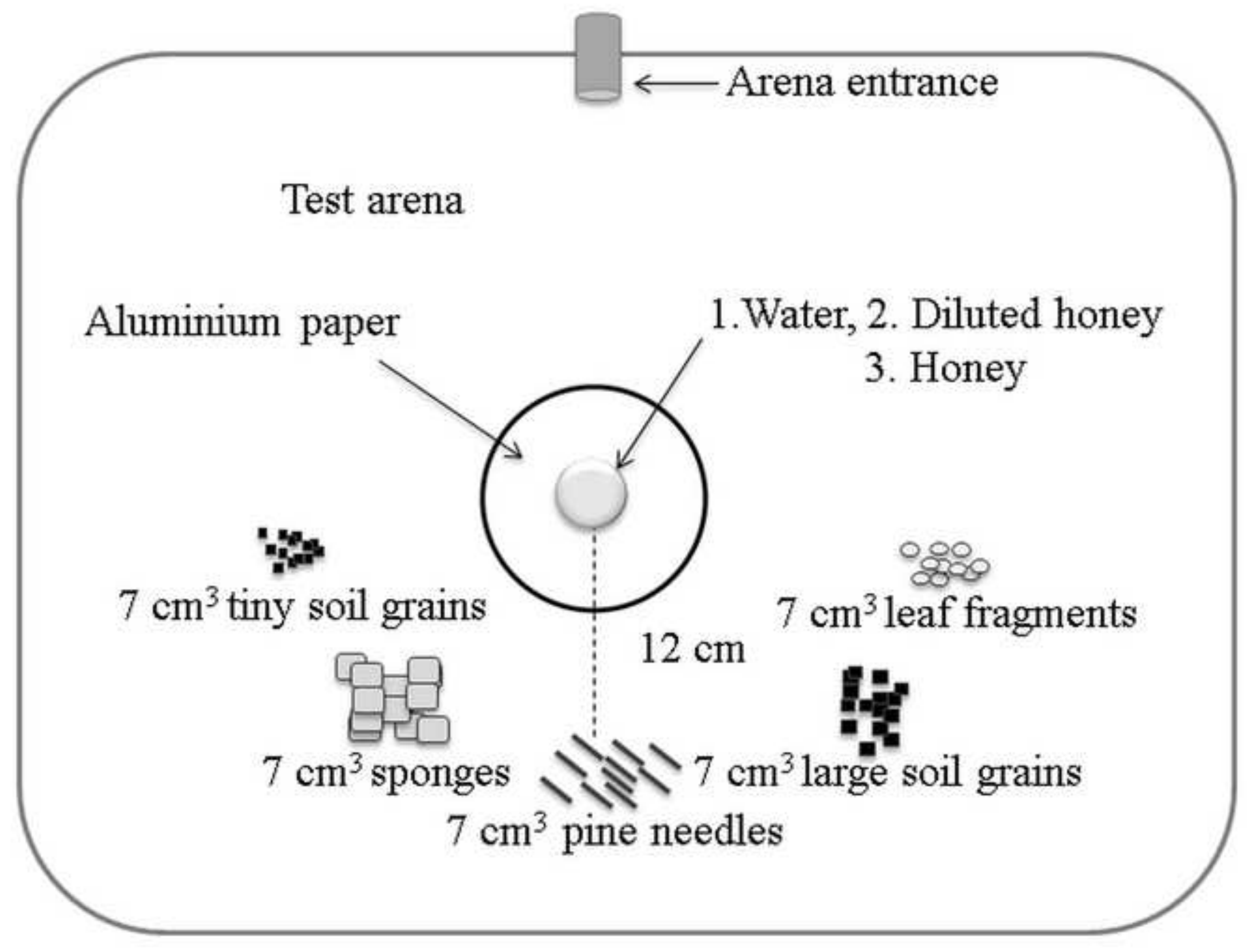




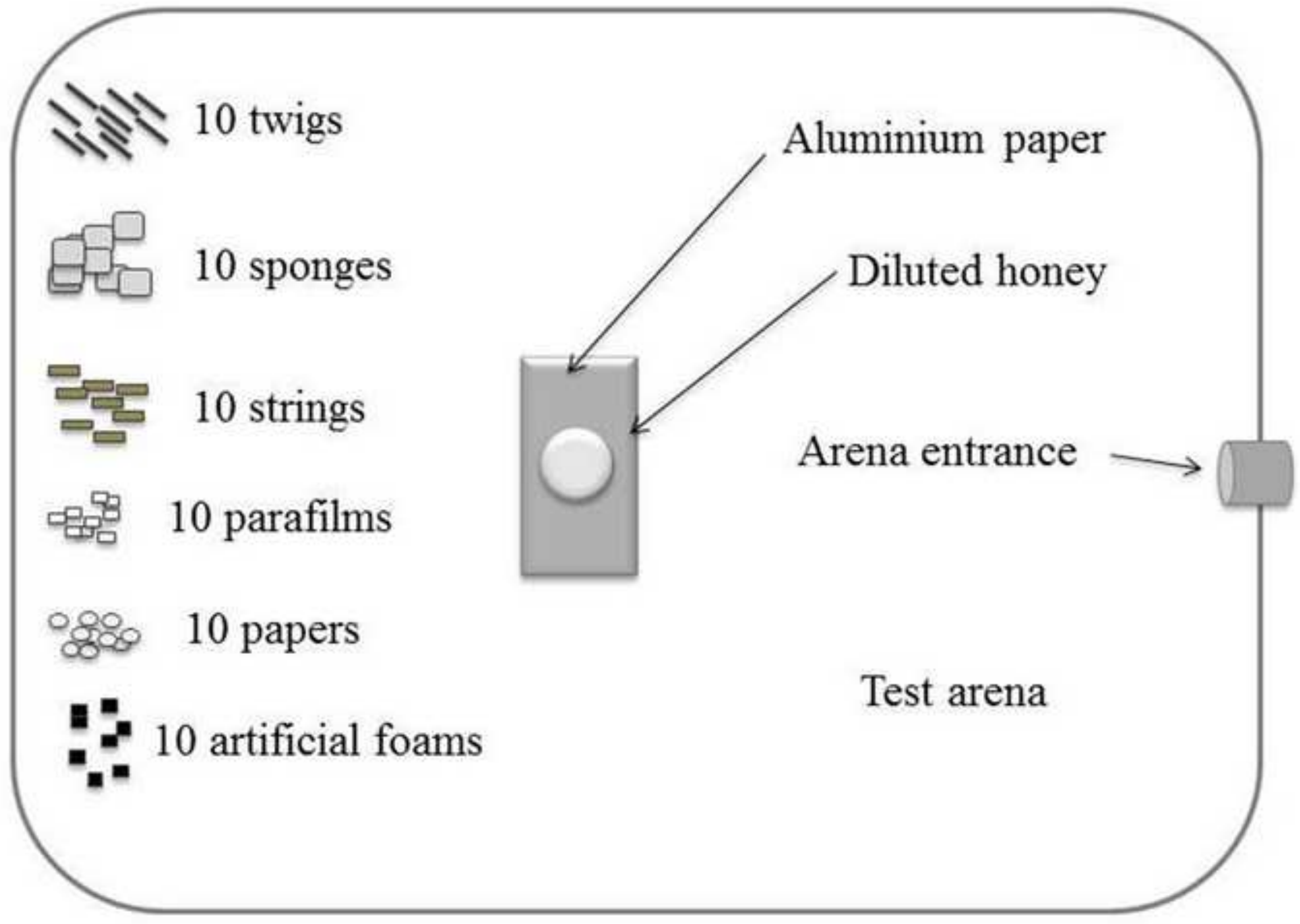



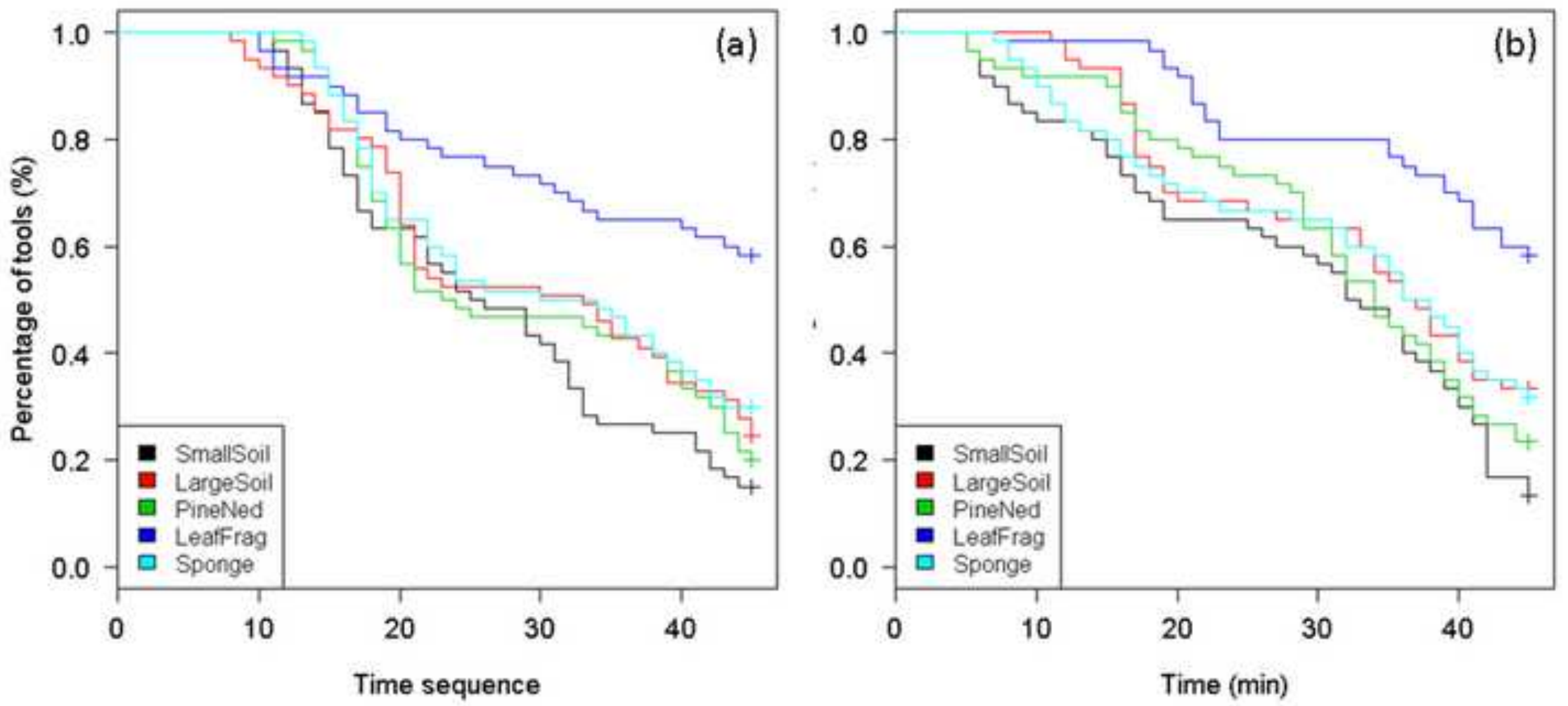

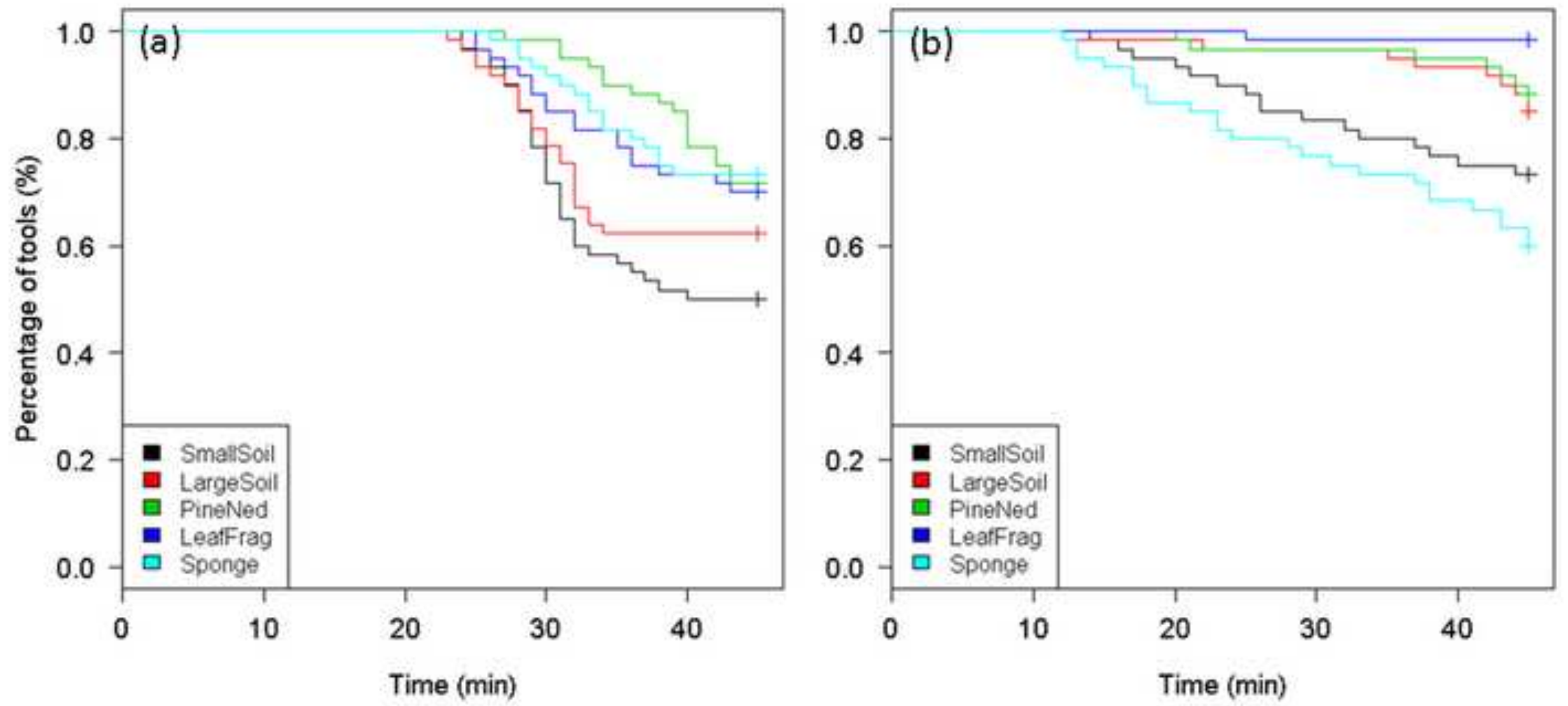


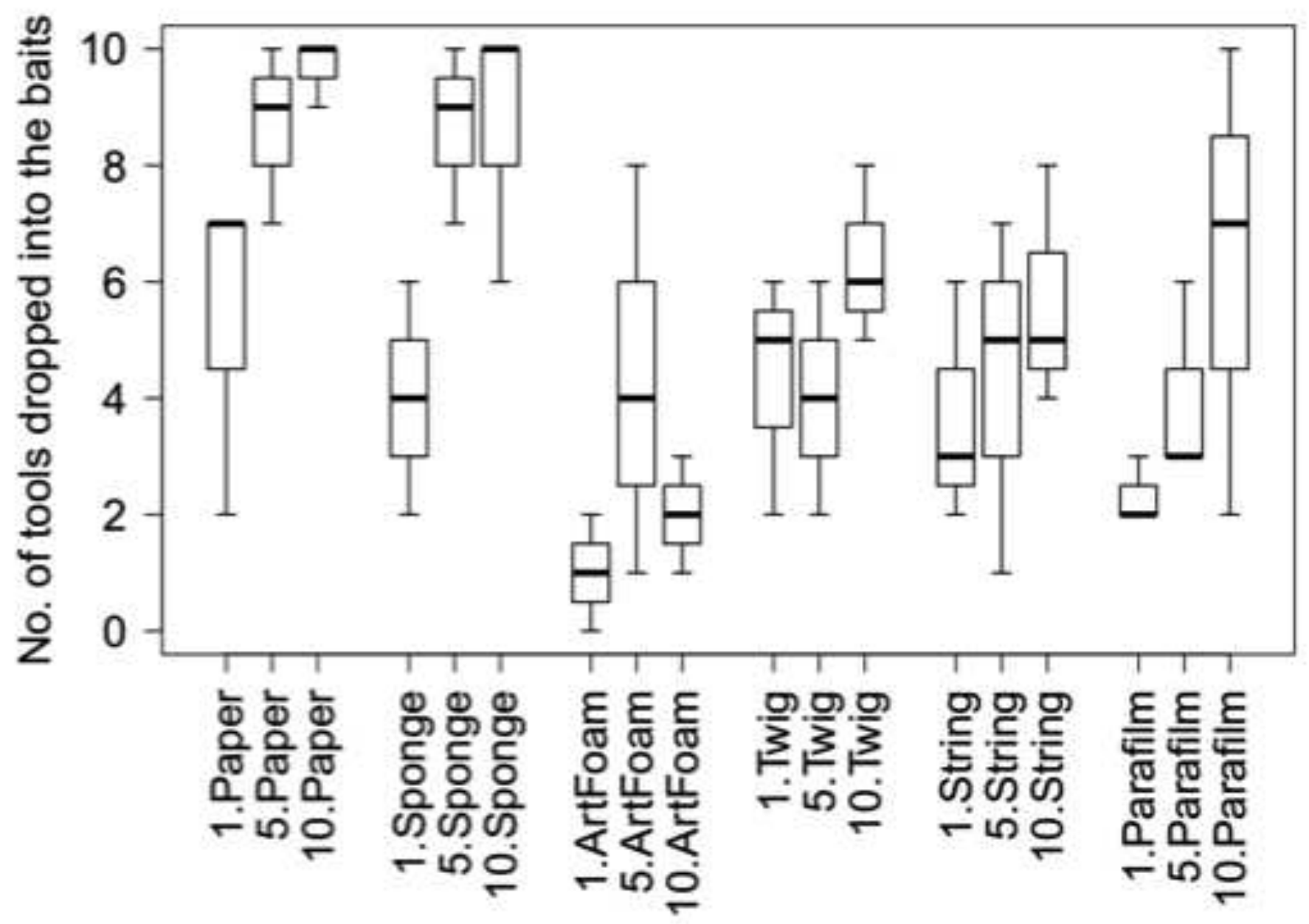

Soaking power 


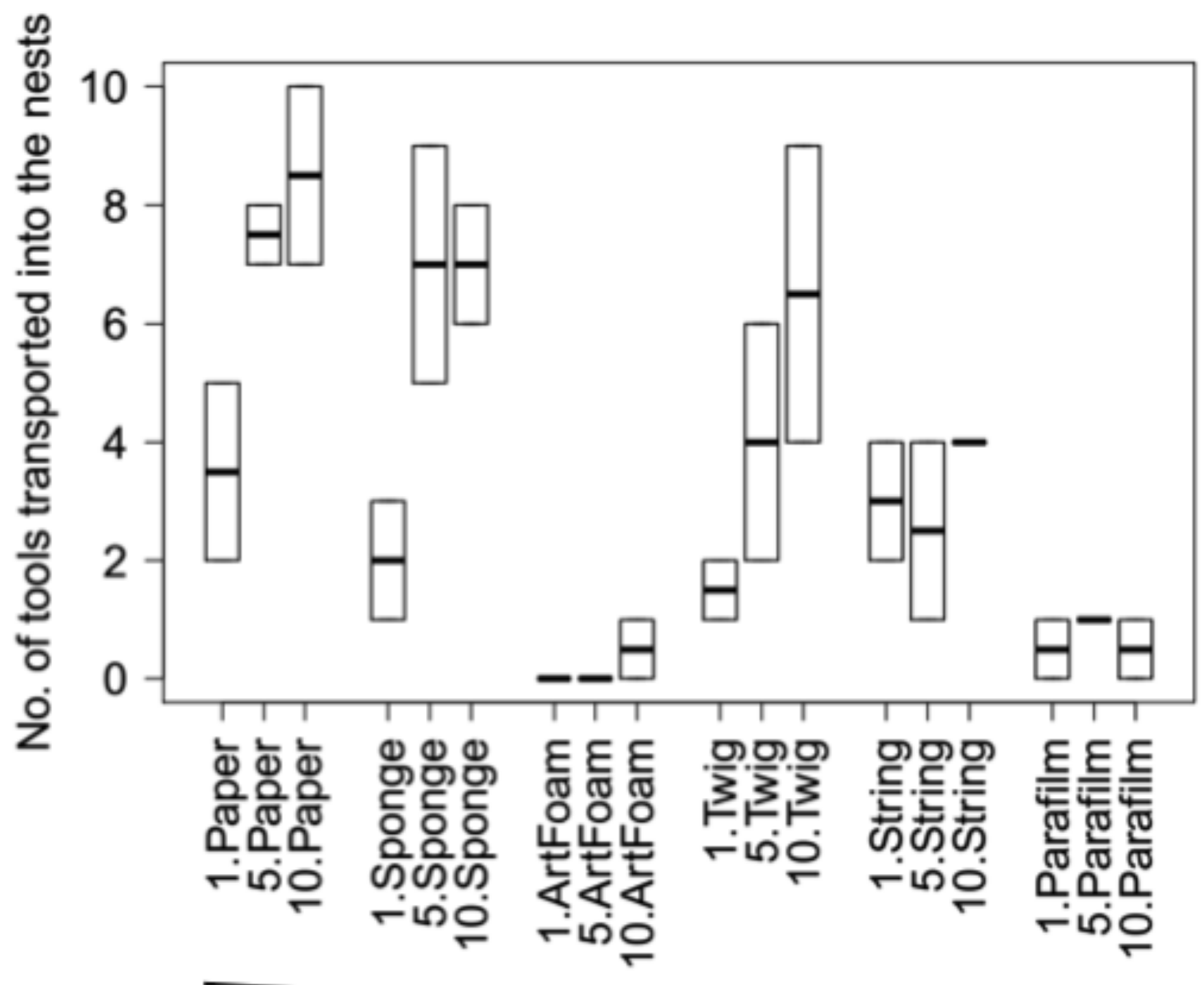

Soaking power 
Figure 1A

Click here to download high resolution image
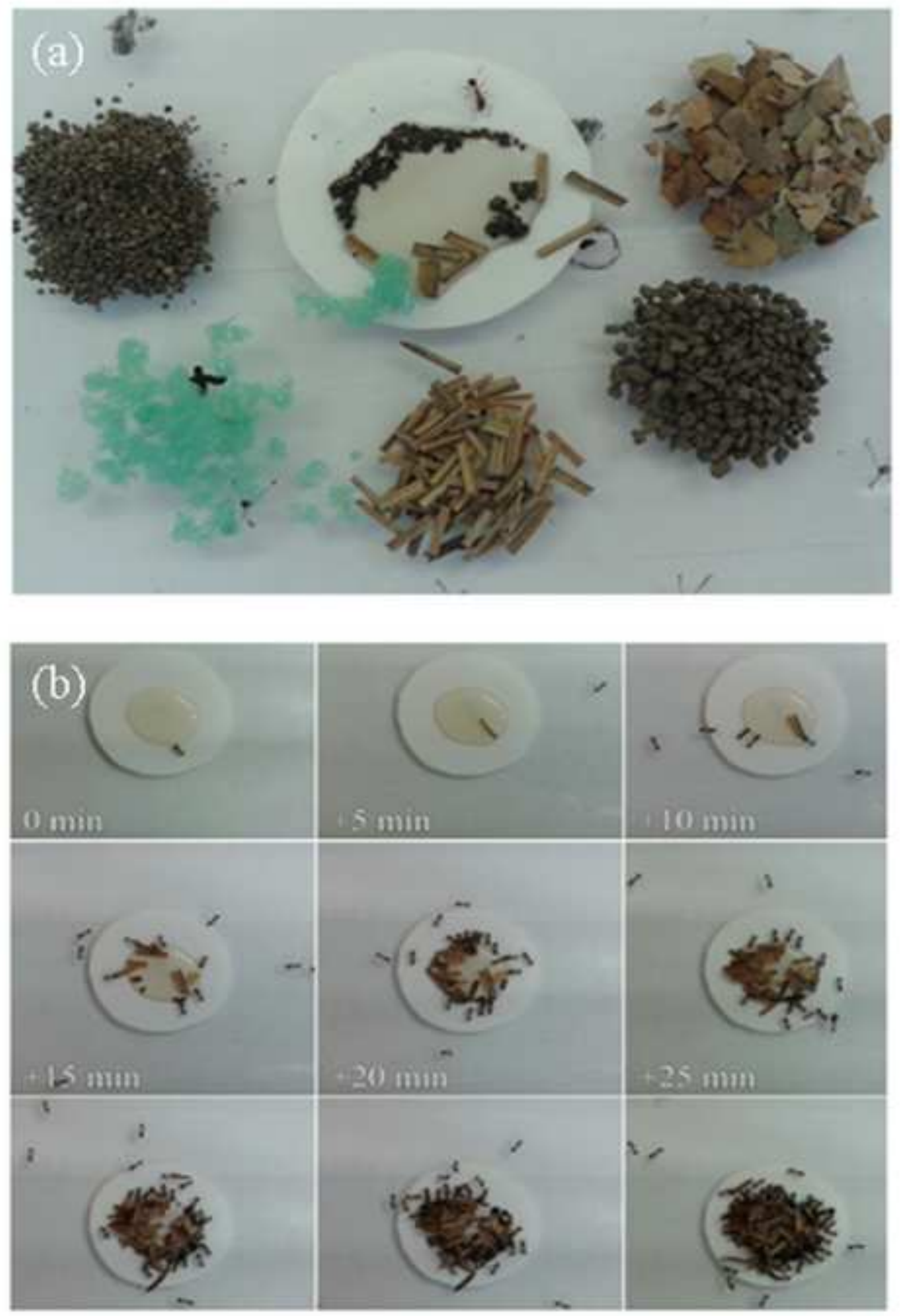
Figure $2 \mathrm{~A}$
Click here to download high resolution image
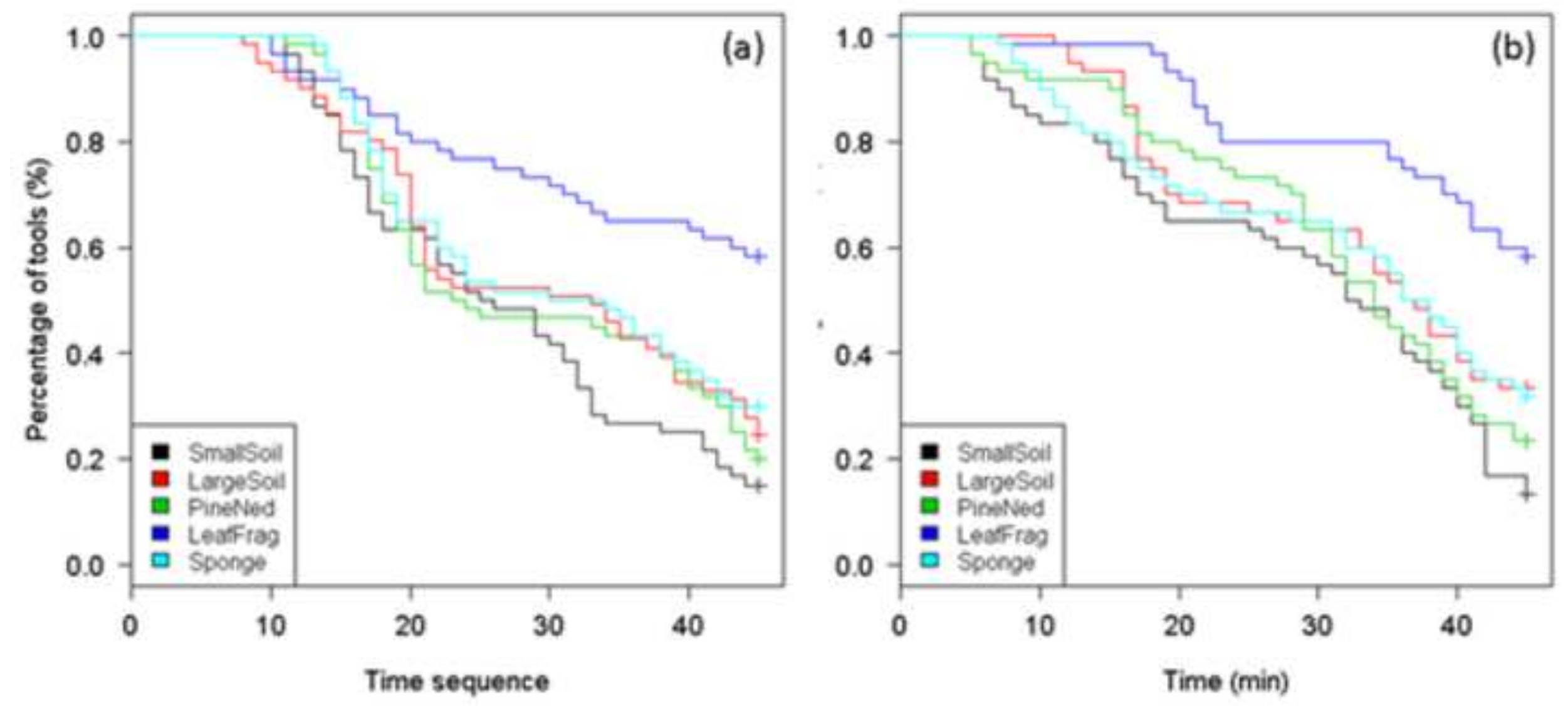
Click here to download high resolution image
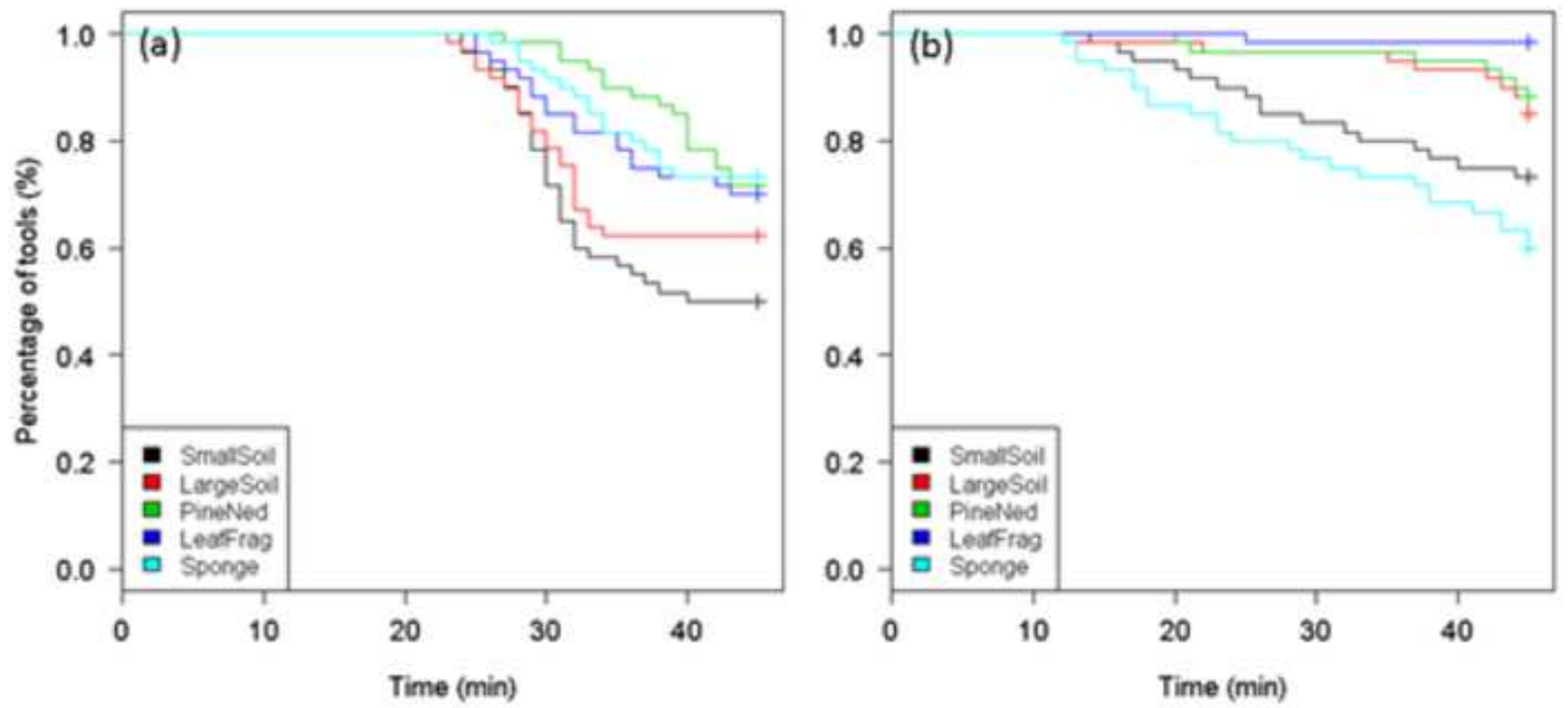

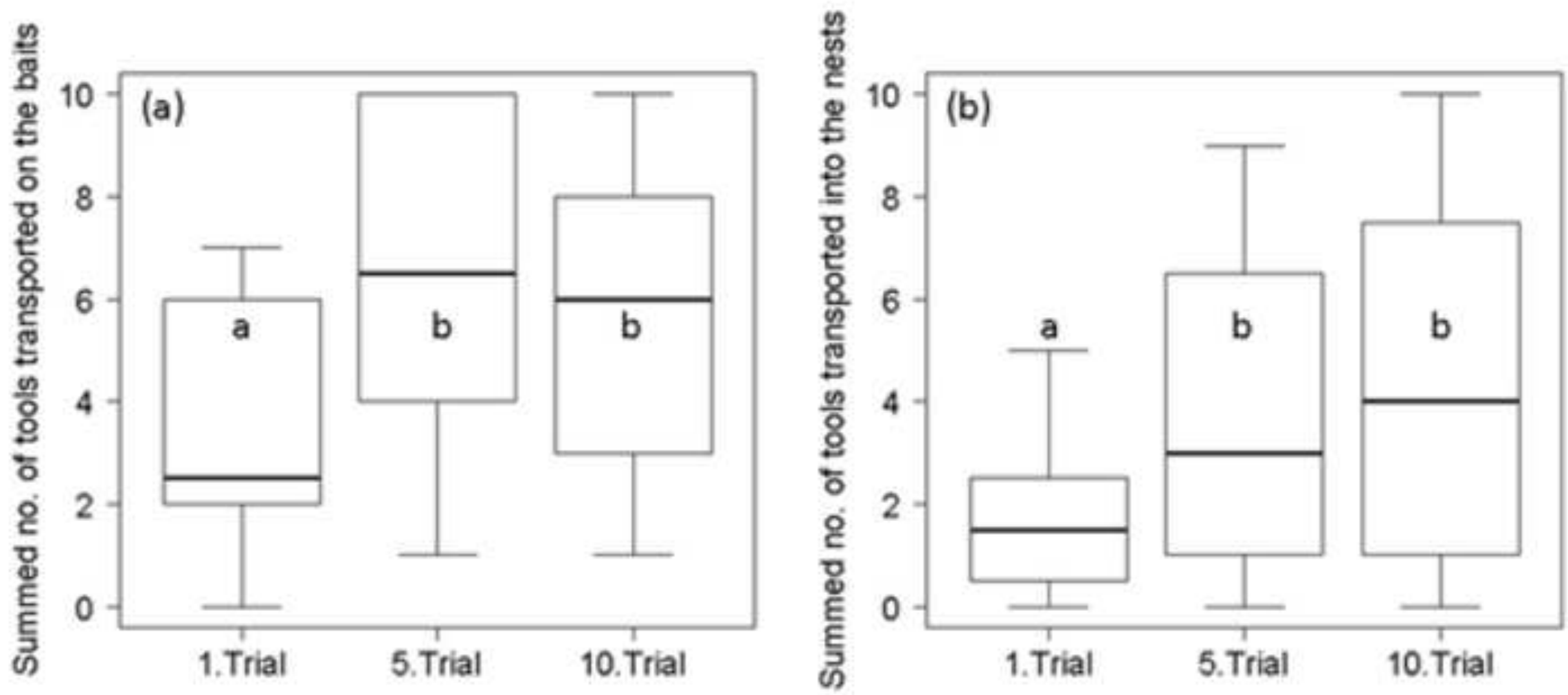

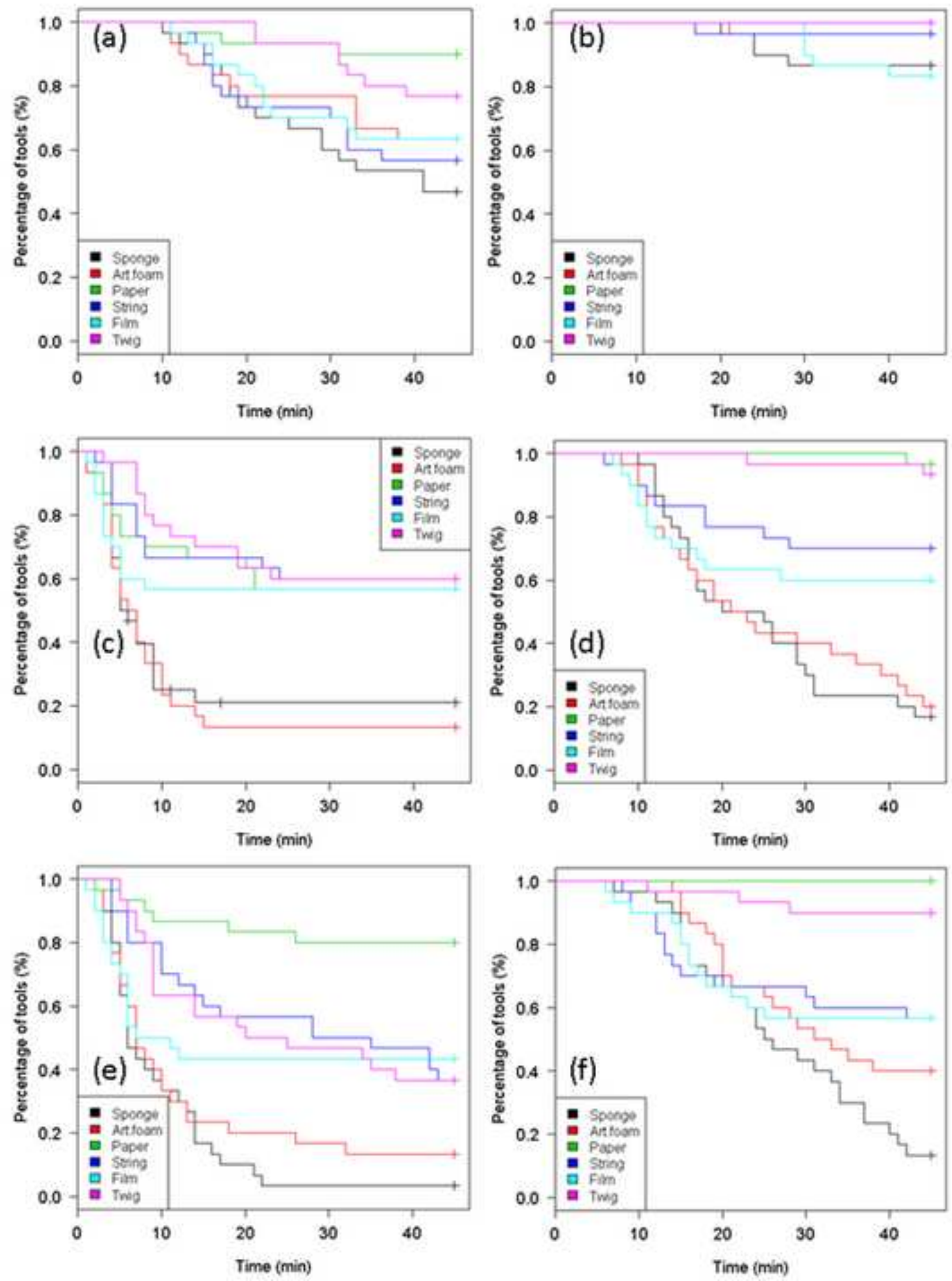
Publicity Photograph (Optional)
Click here to download high resolution image

A

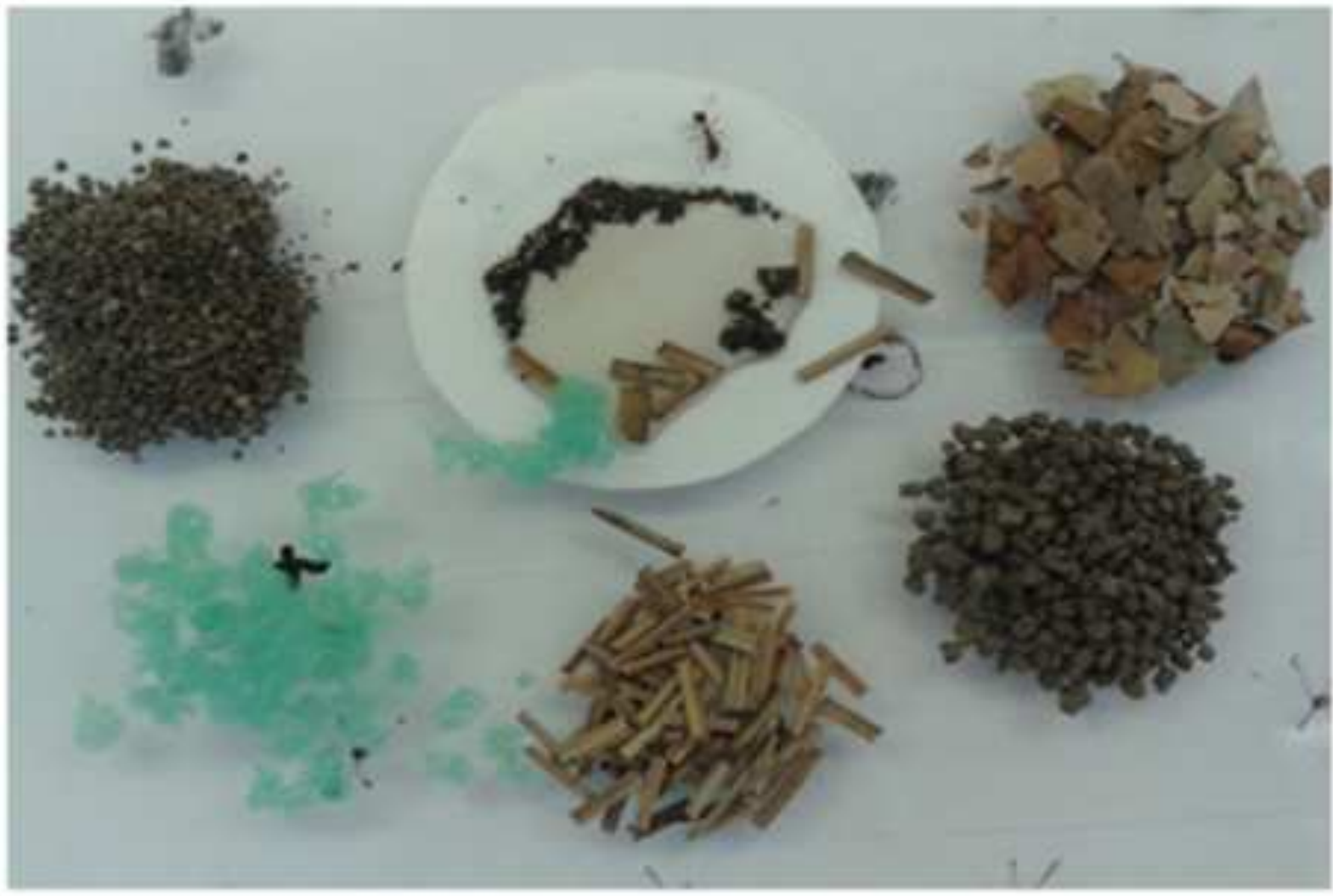

B

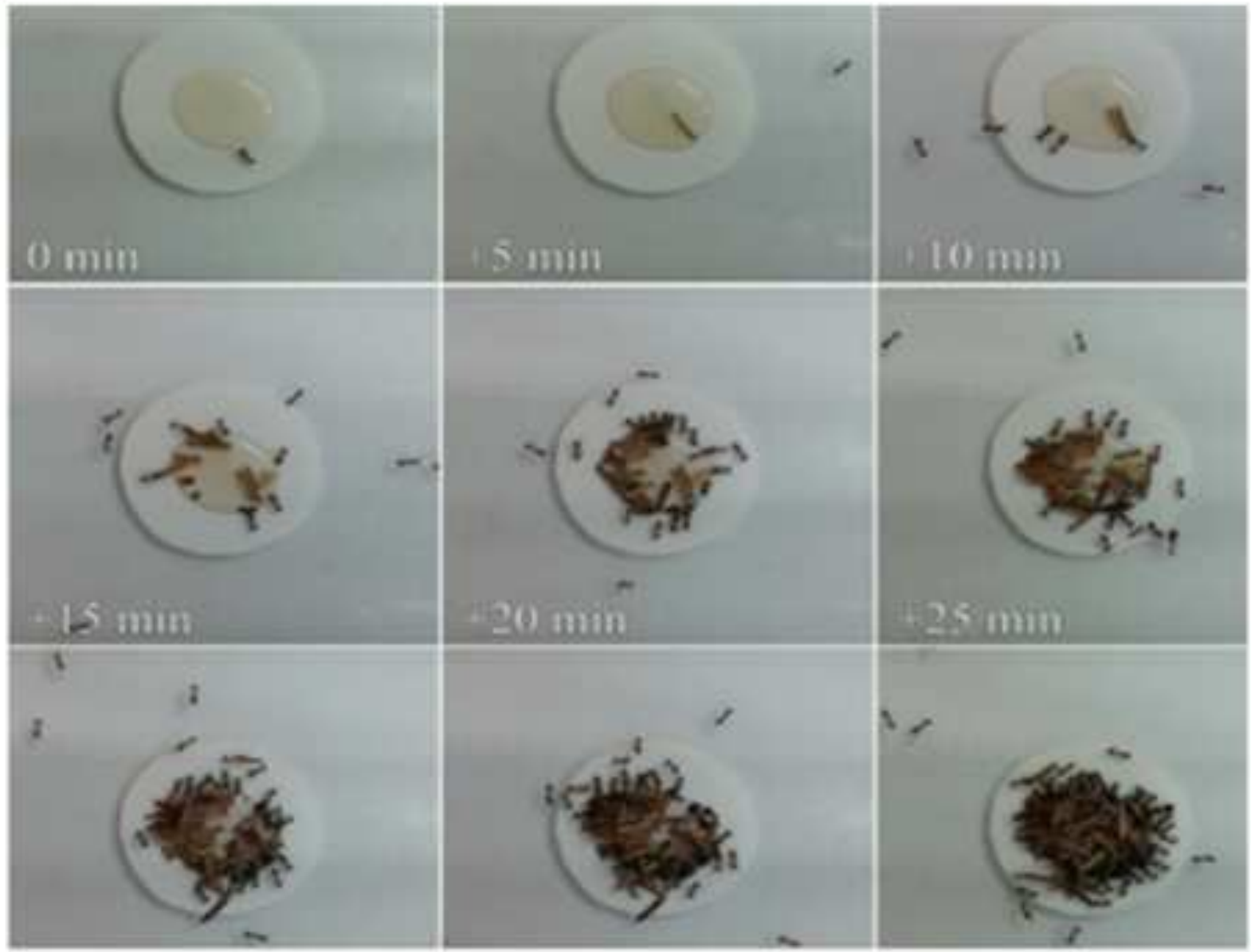

